\title{
A CADAVERIC STUDY OF AZYGOS VENOUS SYSTEM
}

\section{Shilpa *1, K R Dakshayani ${ }^{2}$.}

${ }^{* 1}$ Postgraduate, Department of Anatomy, Mysore Medical College \& Research Institute, Mysore. Karnataka, India.

${ }^{2}$ Professor \& Head, Department of Anatomy, Mysore Medical College \& Research Institute, Mysore. Karnataka, India.

\section{ABSTRACT}

Background: The azygos venous system consists of the azygos vein on the right side and the hemiazygos and accessory hemiazygos on the left side. The latter two are said to be the tributaries rather than the equivalent of the azygos vein. This unpaired venous system is said to be full of anatomical variations and hence of much clinical significance.

Aim: To study and report the prevalence of any anatomical variation of azygos venous system.

Materials and Methods: The present study was carried out in the Department of Anatomy, MMC \& RI, Mysore, over a period of 2 years. A total of 20 cadavers irrespective of age and sex were dissected for study purpose. The entire course of the azygos venous system in these 20 cadavers was carefully dissected and documented.

Observations: In present study among 20 cadavers, 2 adult male cadavers showed variation during dissection of posterior thoracic wall, we found that in one cadaver azygos vein running on left side of vertebral column, hemiazygos and accessory hemiazygos veins were absent. In another cadaver we found that arch of azygos on left side with osteophytic changes of vertebral column.

Conclusion: Venous abnormalities often complicate mediastinal surgery with intra operative hemorrhage. Prior knowledge of possible anatomical variations may help the surgeons to reduce the risk of such events. Also presence of such variations may lead to misinterpretation of thoracic CT and MRI findings of the posterior mediastinum.

KEY WORDS: Azygos vein, Hemiazygos vein, Accessory hemiazygos vein.

Address for Correspondence: Dr. M Shilpa, Postgraduate, Department of Anatomy, Mysore Medical College \& Research Institute, Mysore. Karnataka, India. Mobile No: 7411543525

E-Mail: shilpa_ramling@yahoo.co.in

\section{Access this Article online}

\section{Quick Response code $\quad$ Web site: International Journal of Anatomy and Research ISSN 2321-4287 www.ijmhr.org/ijar.htm}

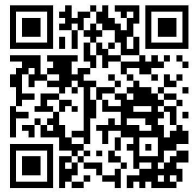

DOI: $10.16965 /$ ijar.2017.317
Received: 22 June 2017

Peer Review: 22 June 2017

Revised: None
Accepted: 03 Aug 2017

Published (O): 31 Aug 2017

Published (P): 31 Aug 2017

\section{INTRODUCTION}

Azygos venous system includes those veins which are straight in course, paravertebral in position, and not accompanied with corresponding arteries [1]. These are provided with valves; drain most of the blood from back and from the thoracic and abdominal walls. The azygos system communicates with the vena caval system in front, and with vertebral venous plexuses behind [1]. The terminal veins of this system are the azygos, hemiazygos and accessory azygos veins. The azygos vein is inconstant in origin. On developmental backgrounds, it may arise as lumbar azygos vein. If it does not arise as lumbar azygos, then trunk is formed by the union of the right sub costal and right ascending lumbar 
veins [1]. In the thorax, the azygos vein passes upwards in front of the lower eight vertebra in the posterior medistinum, opposite the fourth thoracic vertebra, it arches forwards above the root of the right lung and pierces the fibrous pericardium. The arch of azygos vein is a content of middle medistinum.Sometimes there may be variation in termination the arch of azygos splits the apex of right lung and lodges in a fissure where it is suspended by a mesentery [2]. Medial part of the split apex is known as the lobe for azygos vein of right lung. The hemiazygos vein begins by the union of the left ascending lumbar and left sub costal veins, and communicates below with the left renal vein. The accessory azygos vein begins as a continuation of the left fourth posterior intercostals vein, and receives the blood from the left fifth, sixth, seventh intercostals veins as it descends. Finally it terminates in the azygos vein opposite $\mathrm{T7}$ vertebra [2]. The azygos vein is a collateral venous pathway, becoming a vital shunt if major pathways of venous return are obstructed [3].

Fig. 1: the azygos vein is formed by right and left ascending lumbar vein, its course is on the left side of vertebral column, right and left posterior intercostal veins directly draining into azygos vein, absence of hemiazygos and accessory hemiazygos veins.

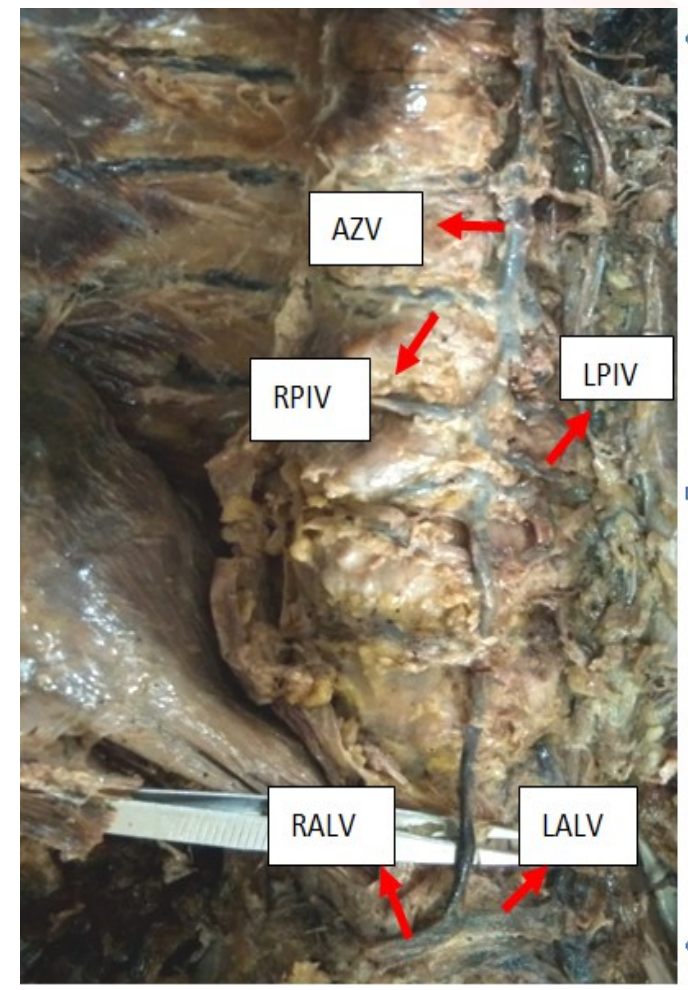

AZV- Azygos vein on left side, RPIV-Right posterior intercostal vein, LPIV-Left posterior intercostal vein directly draining into azygos vein, RALV-Right ascending lumbar vein, LALV- Left ascending lumbar vein.

\section{MATERIALS AND METHODS}

A total of 20 cadavers irrespective of age and sex were obtained from the Department of Anatomy, MMC \& RI, Mysore, over a period of 2 years. The entire azygos venous system (azygos vein, hemiazygos vein, accessory hemiazygos vein) was carefully dissected from its formation, course, tributaries and termination. Following observations were made.

\section{RESULTS}

In the present study, the origin, course and termination of azygos venous system was noted. Out of 20 cadavers $2(20 \%)$ cadavers showed following variations.

One (1) adult male cadaver showed variation in course of azygos vein, absent hemiazygos and accessory hemiazygos vein.

One (1) cadaver showed variation in arch of azygos vein.

Fig. 2: The azygos vein is on the left side and arch of azygos is also on left side arching on left lung but it deviates to right side.The vertebral column shows osteophytic lesions which may be one of the reasons for variation in course of azygos vein.

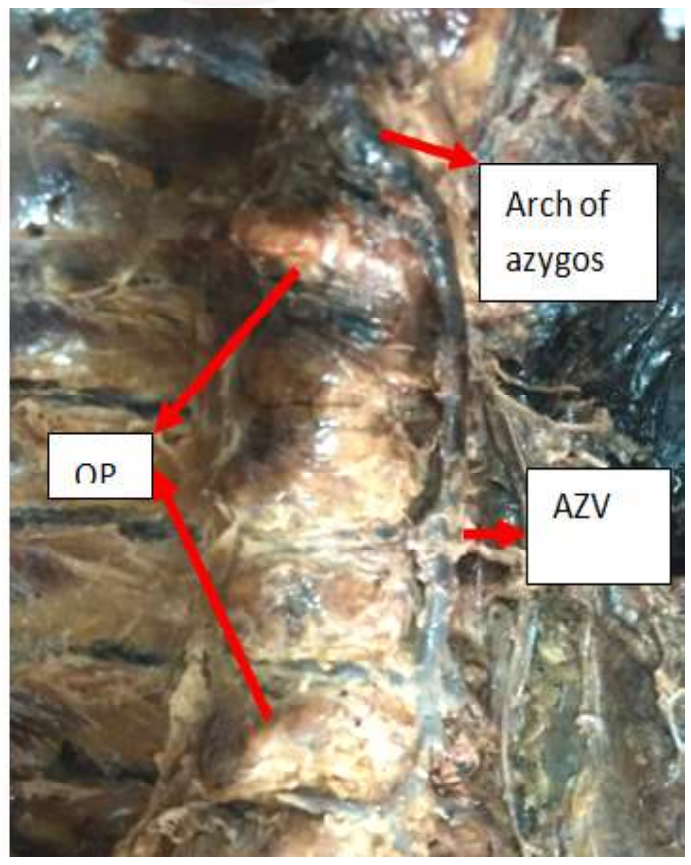

AZV-Azygos vein, Arch of azygos on left side, OP-Figure also shows osteophytic changes in the vertebral column.

\section{DISCUSSION}

The veins of the azygos system vary greatly in mode of origin, course, numbers of tributaries and anastomoses, and nature of termination. The azygos vein system can take different 
courses [2]. Piciucchi et al illustrated in his study the spectrum of normal and pathological changes of the azygos venous system, with related changes of the size, flow and position in relation to its development for example, The agenesis of the azygos vein occurs when the superior segment of the right supracardinal vein fails to develop. The azygos vein is a collateral venous pathway, becoming a vital shunt if major pathways of venous return are obstructed. In azygos continuation, the azygos vein becomes significantly enlarged due to inferior vena cava interruption. Fibrosing mediastinitis is an underestimated acquired disorder and induces a variable engorgement of collateral veins [3]. Kutoglu et al reported in his research, the diameters and levels of the azygos vein, the hemiazygos vein, the accessory hemiazygos vein and the superior intercostals vein were investigated and classified in Anson's system with a basis of vertical and horizontal connections in the azygos venous system the classification included primitive or embryological types, transient type, unicolon type as three basic types and their 11 subgroups [4]. Kagami $\mathrm{H}$ has reported in his study of 36 cadavers, he observed crossing of azygos vein from right to left in 22 cadavers, midline in 3 cadavers and on the right side only in the remaining cadavers [5].

Kagami $\mathrm{H}$ divided the course of azygos vein into 2 types depending upon his study Semicircular/ sigmoid course: In this type, the azygos vein runs on the right side up to certain vertebral level then crosses the midline and runs on the left side.

Straight course: In this type, azygos vein courses on the right side as this is described as the normal course [5].

The present study showed sigmoid course in figure 2. Lydia SQ et al have reported in his study that absence of hemiazygos vein. In this study the author has reported the underdeveloped hemiazygos veins and the direct opening of $4^{\text {th }}$, $5^{\text {th }}, 6^{\text {th }}$ and $7^{\text {th }}$ left posterior intercostal veins into the azygos vein [6]. In the present study, there is absence of hemiazygos and accessory azygos veins.Similarly Bergmann et al, have reported variations of azygos veins in $26 \%$ of cases no hemiazygos vein was present. A left azygos vein discharged the left subclavian vein [7]. Coscina
WF have reported two azygos veins continues with IVC, these abnormalities are generally explained by the embryological development [8]. Suat Keskin reported a rare case of independent right and left azygos veins, with absence of the hemiazygos, in a 52-year-old woman. The azygos vein ascended upward and to the left to reach the midline at the level of the $9^{\text {th }}$ thoracic vertebra. After ascending till $5^{\text {th }}$ thoracic vertebra, it gradually inclined to the right of midline and terminated by opening into the superior vena cava at the level of the $3^{\text {rd }}$ thoracic vertebra [9]. In Mahato, NK case report there was persistent cranial part of the left posterior cardinal vein. This persistent cephalic part of the posterior cardinal vein serves as a communication between the superior hemi-azygos vein to the brachio-cephalic vein on the left side. The existence of such an anomaly, the position of this vein and its proximity to the structures near the arch of aorta should be taken into consideration to avert radiological mis-diagnosis and surgical complications [10]. Srinivasa rao reported in 2 male cadavers a communicating vein is present between left brachio-cephalic vein and the azygos vein.

The accessory hemi-azygos vein is absent and the hemi-azygos vein is present draining into the azygos vein. In 2 male cadavers there were 3 transverse channels connecting the accessory hemiazygos and hemiazygos with the azygos vein [11]. Badagabettu S N, literature survey also revealed a case where the hemiazygos vein was absent with the presence of right and left azygos veins [12].

In Teresa Rani study, 50 cadavers have been observed for the mode of formation of Azygos vein. In this study different aspects of azgos venous system have been reported like the level of termination of the Azygos vein between third and fourth thoracic vertebra. Hemiazygos, the left lower complement of the Azygos vein formed by the union of left ascending lumbar and subcostal veins usually but in this study in one case it arises from the back of Inferior vena cava ascends up and receives the left ascending lumbar and subcostal veins before it joins the Azygos. Hemi azygos vein is crossing the midline at T8 towards the right side in $60 \%$ cases, at T7 in $26.66 \%$, at T9 in $10 \%$, at T10 in 3.33\% [13]. 
In Uma shivanal study, normal azygos venous system was found in 8 specimens accounting for $80 \%$. Variations were found in 2 specimens (20\%); one specimen presented with connection between accessory hemiazygos vein and hemiazygos vein, 3 transverse channels across vertebral column and the other specimen showed absence of accessory hemiazygos vein and shifting of azygos vein towards midline [14].

\section{CONCLUSION}

This unpaired venous system is said to be full of anatomical variations and hence of much clinical significance. Venous abnormalities often complicate mediastinal surgery with intra operative hemorrhage. Prior knowledge of possible anatomical variations may help the surgeons to reduce the risk of such events. Some variations of the azygos venous system can easily be confused with pathological conditions such as aneurysms, tumors and enlarged lymph nodes. Also presence of such variations may lead to misinterpretation of thoracic CT and MRI findings of the posterior medistinium tumors.

\section{Conflicts of Interests: None}

\section{REFERENCES}

[1]. Datta AK. Thorax and abdomen. In: Datta AK, eds. Essentials of Human Anatomy. 9th ed. Kolkata: Current Books International; 2010;100-102.

[2]. Susan Standring. Azygos vein. In: Susan Standring, eds. Gray's Anatomy: the Anatomical Basis of Clinical Practice. 40th ed. London: Churchill Livingstone Elsevier; 2008;939-940.

[3]. Piciucchi S, Barone D, Sanna S, Dubini A, Goodman $L$, Oboldi $D$, et al . The azygos vein pathway: $A n$ overview from anatomical variations to pathological changes 2014 Oct;5(5):619-628.

[4]. Kutoglu T, Turut M, Kocabiyik N, Ozan H, Yildirim M. Anatomical analysis of azygos vein system in human cadavers. Rom J Morphol Embryol. 2012;53(4):1051-6.
[5]. Kagami H, Sakai $\mathrm{H}$. The problems in the arrangement of the azygos vein. Okajimas Folia Anatomy, Japan 1990;67(2-3):111-114p.

[6]. Lydia SQ, Bhagath KP, Anitha G, Thejodhar P, Biswabina R, Suhani SD, et al. Anomalous azygos venous system in a south Indian cadaver: a case report. Cases J. 2009; 2:6746.

[7]. Bergman RA, Thompson SA, Afifi AK, Saadeh FA. Compendium of Human Anatomic Variation: Catalog, Atlas and World Literature. Baltimore, Md, USA: Urban \& Schwarzenberg; 1988.

[8]. Coscina WF, Arger H, Mintz MC, Coleman BG: Concurrent duplication and azygos continuation of the inferior vena cava.1986, J Comput Tomogr 1986;10:287-290.

[9]. Mahato, NK. Anomalous accessory hemi-azyos system with persistent cranial segment of posterior cardinal vein - A case report Braz. J. Morphol. Sci., 2009;26(3-4):177-179.

[10]. Suat Keskin, Zeynep Keskin, and Nevin Sekmenli.The Independent Right and Left Azygos Veins with Hemiazygos Absence: A Rare Case Presentation http://dx.doi.org/10.1155/2013/282416.Volume 2013 , Article ID 282416, 3 pages.

[11]. Badagabettu S N, Shetty P, D'Souza M R .J Cardiovasc Echograph. A Unique Variation of Azygos System of Veins. 2016; 26(2):61-64.

[12]. Y.Srinivas Rao. Anatomical variations of the azygos venous system. Int J BiolMed Res. 2014;5(4):45354538.

[13]. B. Vijaya Nirmala, Teresa Rani S. Study of Azygos System and its Variations. Journal of Evolution of Medical and Dental Sciences 2015;4(33):56525657.

[14]. Shivanal U, Geethanjali HT. Anomalous azygos veins - its embryological basis and clinical significance. Int J Res Med Sci 2015;3:2323-6.

How to cite this article:

M Shilpa, K R Dakshayani. A CADAVERIC STUDY OF AZYGOS VENOUS SYSTEM. Int J Anat Res 2017;5(3.2):4299-4302. DOI: 10.16965/ijar.2017.317 